\title{
Modelo de Excelência da Gestão como uma das bases para a Inovação, algo imprescindível para Micro e Pequenas Empresas
}

Title: Excellence Management Model as one of the bases for innovation, something essential for Micro and Small Companies

Paula Andréa de B. Franco Brito

Escola Politécnica de Pernambuco

Universidade de Pernambuco

50.720-001 - Recife, Brasil

paulabrito2808@gmail.com

\author{
Ana de Fátima Braga Barbosa \\ Escola Politécnica de Pernambuco \\ Universidade de Pernambuco \\ 50.720-001 - Recife, Brasil \\ afbb.direito@yahoo.com.br
}

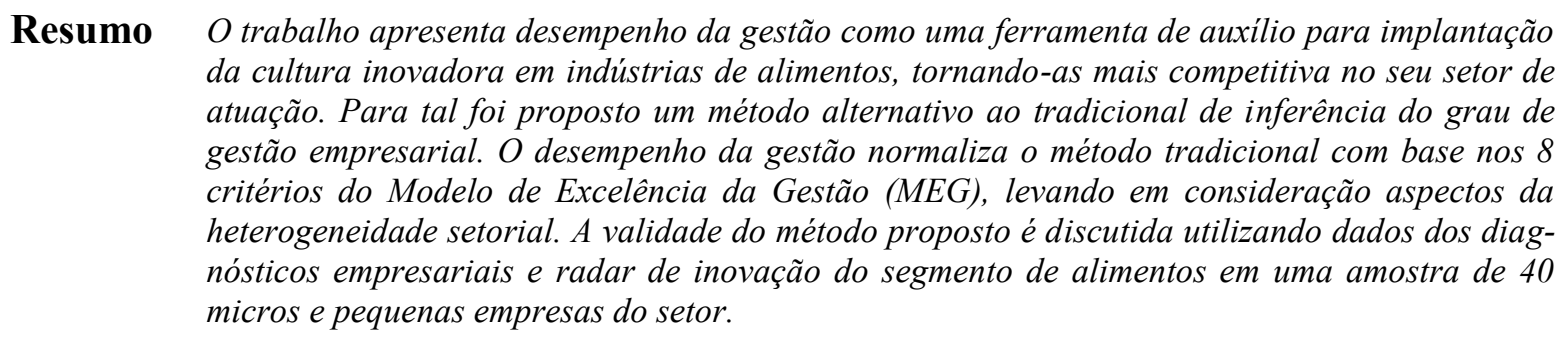

Palavras-Chave: Desempenho da Gestão, Inovação, Radar da Inovação, Micro e Pequenas Empresas, Grau da Inovação e Critérios de excelência

\begin{abstract}
This document presents the performance of managements an important tool to implement a new culture focused on innovation, it was tested in Food Industries, making them more competitive in the operating segment. This method is proposed as an alternative to the traditional inference of business management grade. The performance of management normalizes the traditional method based on 8 criteria of the Excellence Management Model (which states MEG in Portuguese) taking into account aspects of sectoral heterogeneity. To validate the method it was proposed and discussed using the data collected from several companies and the tool "radar da inovação", considering food sector, in a sample of 40 micro and small companies.
\end{abstract}

Keywords: Performance Management, Innovation, Micro and Small Companies, Innovation Degree and criteria of excellence 


\section{Introdução}

Atualmente, com a globalização da economia, a continuidade das empresas no mercado de atuação está sujeita a capacidade de inovar e melhorar continuamente os seus processos. Para que esse resultado seja alcançado e a organização se torne mais competitiva, é necessária a busca por ferramentas de gerenciamento que sejam eficazes, que proporcione aumento da produtividade e qualidade dos produtos/serviços e processos e isso tem sido um grande desafio. Gerar resultados positivos não é uma tarefa fácil e demanda que toda organização esteja envolvida. É importante que todos participem dos mesmos valores para que um objetivo comum seja alcançado. Neste sentido, o pensamento sistêmico deve atuar, ou seja, todos os colaboradores devem ter entendimento do todo e isso não envolve apenas os processos e rotinas das organizações, mas, também, o que a marca representa externamente, para o mercado. Esse comportamento proporciona que os profissionais saibam se posicionar $\mathrm{e}$ resolver problemas, que busquem saídas e sugiram melhorias para o negócio. A visão sistêmica é o primeiro tópico tratado pelo Modelo de Excelência da Gestão (MEG). De acordo com a Fundação Nacional da Qualidade (FNQ), a missão do MEG é "estimular e apoiar as organizações brasileiras no desenvolvimento e na evolução de sua gestão para que se tornem sustentáveis, cooperativas e gerem valor para a sociedade e outras partes interessadas".

De modo a se tornarem mais competitivas, as empresas necessitam que as funções básicas representadas pelos diversos departamentos de sua estrutura apresentem resultados excelentes na busca de status de excelência ou classe mundial [1], [2]. As inovações têm sido a nova moeda da competição global na medida em que países competem ferozmente por novos mercados em um contexto onde a capacidade de criar novas ideias é considerada como marca registrada do sucesso nacional. A competição tem apontado para captação de capital de risco associado à pesquisa e desenvolvimento $(\mathrm{P} \& \mathrm{D})$ adicionados a talentos inovativos e assim, delimitando regiões densas de inovação de onde emergirão oportunidades. A inovação passa a ser uma força orientadora das políticas públicas de muitos países.

Diante da importância do crescimento do tema inovação no desenvolvimento das nações, diversos pesquisadores propuseram tipologias para medir o grau de inovação organizacional. Entre tais pesquisadores destacam-se os seguintes: Schumpeter [3] e Sawhney \& Chen [4]. Tal avanço metodológico culminou no radar de inovação, uma ferramenta composta de 13 indicadores aplicáveis a praticamente toda organização. A crítica que se destaca nesse artigo é demonstrar que as empresas que tem um mínimo de gestão empresarial implantada em seus pro- cessos corroboram com mais estrutura para inovar. A forma aqui sugerida é utilizar uma média simples de 8 critérios, sendo eles Liderança, Estratégias e Planos, Clientes, Sociedade, Informações e Conhecimento, Pessoas, Processos e Resultados. A forma de medir tem como pressuposto básico que para uma empresa ser inovadora necessariamente teria que se desenvolver em todas as dimensões dos diagnósticos empresarial e radar da inovação indicadas por essa forma de avaliar. No entanto, identificam-se na realidade que as empresas não necessariamente têm desenvolvidas todas as dimensões propostas nos dois questionários. Queremos mostrar um índice de gestão empresarial e inovação setorial no segmento de alimentos, podendo ser aplicado às micro e pequenas empresas (MPE). Este é o principal objetivo deste trabalho, que apresenta um índice de desempenho da gestão e inovação setorial partindo do modelo do diagnóstico empresarial e radar da inovação.

\section{Justificativa}

A inovação pode ser tomada como uma estratégia fundamental para desenvolver o bem estar da sociedade por meio de sistemas e processos de produção mais eficiente e como forma de utilizar melhor os recursos definidos por políticas públicas de desenvolvimento, assim como, tornar uma organização mais competitiva. Todo o processo de desempenho de gestão de uma organização visa preparar a empresa para alcançar os objetivos, ganhar competitividade, obter melhor visibilidade do mercado e base para implantar o processo de gestão da inovação. Para a implantação e manutenção da inovação, se faz necessário a base da gestão empresarial, visto que a cultura inovadora os considera como norteadores para obter resultados satisfatórios.

\section{Objetivos}

\subsection{Geral}

O estudo mostra como o baixo acompanhamento de atividades de gestão consideradas primárias de micro e pequenas empresas pode influenciar no processo de gestão da inovação e proporcionalmente retardar o processo de P\&D, atrapalhar a manutenção no mercado de atuação e deixá-las menos competitivas.

\subsection{Específicos}

(a) Compreender o Modelo de Excelência da Gestão e sua importância para as organizações;

(b) Definir o tema inovação de acordo com o estudo realizado;

(c) Mensurar inovação em micro e pequenas empresas; 
(d) Apresentar as dimensões da inovação;

(e) Conceituar os fundamentos da excelência da gestão;

(f) Pesquisar as dimensões de inovação e critérios da excelência da gestão em micro e pequenas empresas.

\section{Referencial Teórico}

\subsection{Inovação - definições}

O termo inovação pode ser definido de várias formas dependendo da perspectiva de interesse. No entanto, a maioria das definições apresenta uma visão restrita e geralmente orientada para tecnologia com foco em P\&D, desenvolvimento de novo produto ou a dicotomia de produtos/processos.

Garcia \& Calantone [5] definem inovação como "processos interativos utilizados para explorar o potencial de mercado de uma invenção baseado em tecnologia". Este processo simula graus variados de inovação e necessita uma tipologia para descrever tipos diferentes de inovação. Semelhantemente, McDermott \& O'Conner [6] definem inovação como "uma nova tecnologia ou combinação de tecnologias que oferecem benefícios que valem a pena". Esta visão enfatiza inovação como um processo de introdução no mercado de uma tecnologia nova por adoção e difusão.

Neste fluxo, inovação é compreendida como P\&D ou invenção dirigida à tecnologia. Em um segundo grupo de definição, inovação passa a representar desenvolvimento de um novo produto. Por exemplo, Hauser [7], Tellis \& Grifo (2006) e Han, Kim, \& Srivastava [8] definem inovação como "o processo de trazer produtos e serviços novos para comercializar”.

Um terceiro grupo de estudos inclui processos na extensão de inovação e a visão de inovação como uma dicotomia de produto/processo. Por exemplo, Tushman \& Nadler [9] definem inovação como "a criação de qualquer produto, serviço e processo que são novos a uma unidade de negócio". Neste conceito, inovação de processo envolve criar maneiras diferentes de desenvolver produtos novos, melhorando a eficiência do processo. Portanto, baseado nos pontos de vista funcionais da literatura existente, a maioria dos trabalhos de pesquisa na área leva em conta uma relação estreita entre inovação orientada a tecnologia ou produto.

Neste artigo, inovação é entendida como uma ação capaz de gerar valor à organização por meio de um fazer novo para ela, ou seja, inovação implica na mudança de paradigma organizacional interno à empresa, mas não necessariamente uma mudança de paradigma empresarial.
Neste contexto é possível inovar em comercialização dos produtos, desenvolvimento de canais de distribuição, criar novos produtos e/ou processos, desenvolver novas ações de marketing, e outras ações que impactem no valor da empresa de forma sustentável e permanente.

\subsection{Mensurando a Inovação}

A grande dificuldade entre as definições de inovação é estabelecer um procedimento de como medi-la ou definir um processo de como inovar. Garcia Schumpeter [10] apresenta uma tipologia para a inovação baseada em quatro princípios: tecnológico, comercial, organizacional e institucional. Tal autor aborda a inovação de forma ampliada e dá o tom de complexidade do tema.

Outra maneira de estabelecer a inovação é através da holística que foi proposta por Schumpeter [3] de modo a definir dimensões para a inovação. Segundo ele a inovação pode surgir sob a dimensão de um novo produto, de um novo processo, pela procura de novos mercados, desenvolvimento de novas fontes de matériasprimas e pelo estabelecimento de novas estruturas de mercado.

Com base no modelo de Schumpeter [3] define-se a principal referência internacional para a medição da inovação: o Manual de Oslo [11] que permite comparações entre trabalhos relacionados com a inovação a partir das diretrizes propostas. Sawhney [12] propõe uma ferramenta denominada Radar que relaciona as dimensões que pelas quais uma empresa pode procurar caminhos para inovar, como apresentado na Figura 1.

O Radar da Inovação reúne quatro dimensões principais, a saber: ofertas criadas; clientes atendidos; processos empregados; e praça. Tais dimensões compõem a base de referência para determinar a inovação, no entanto, o próprio Sawhney [12] percebeu que as empresas procuram outros caminhos para alcançar patamares mais elevados de competitividade.

\subsection{As dimensões da inovação}

Além das quatro dimensões acima apresentadas por Sawhney [12], mais oito dimensões foram adicionadas, a saber: Plataforma, Marca, Soluções, Relacionamento, Agregação de valor, Organização, Cadeia de fornecimento e Rede. Bachmann e Destefani [13] acrescentaram às 12 dimensões de Sawhney [12] o conceito de ambiente propício à inovação. Tal situação pode ser percebida, entre outros aspectos, pelo aporte de recursos humanos à empresa com formação facilitadora do processo de incorporação e implementação da cultura de inovação. Na Tabela 1 são apresentadas as dimensões da inovação proposta por Sawhney [12] e complementada por Bachmann e Destefani [13]. 


\section{Diagnóstico - Radar da Inovação nos Pequenos Negócios}

Bloco II - Determinaçăo do Radar da Grau de Inovaçăo Indústria

\section{A - Dimensăo Oferta}

\begin{tabular}{|c|c|c|}
\hline Item 1 - Novos mercados (RESERVADO) & & Evidência \\
\hline Item 2 - Novos produtos & & Evidência \\
\hline $\begin{array}{l}\text { A empresa lanç,ou, com sucesso, mais de um novo produto no mercado nos } \\
\text { ütimos } 3 \text { anos. }\end{array}$ & 5 & \\
\hline $\begin{array}{l}\text { A empresa lançou, com sucesso, um novo produto no mercado nos ùltirnos } 3 \\
\text { anoB. }\end{array}$ & 3 & \\
\hline
\end{tabular}

Figura 1 : Parte do questionário Radar da Inovação

\begin{tabular}{|c|c|}
\hline & DIMENSÕES DA INOVAÇÃO \\
\hline Dimensão & Definição \\
\hline Oferta & Desenvolvimento de produtos com características inovadoras. \\
\hline Processos & Redesenho dos processos produtivos de modo a permitir incremento de eficiência operacional \\
\hline Clientes & Identificar necessidades dos clientes, ou novos nichos de mercado. \\
\hline Praça & Identificar novas formas de comercialização e/ou distribuição. \\
\hline Plataforma & $\begin{array}{l}\text { Relaciona-se com a adaptabilidade do sistema de produção face à diversidade de produtos } \\
\text { demandados. }\end{array}$ \\
\hline Marca & Forma como as empresas transmitem aos clientes seus valores. \\
\hline Soluções & Sistemas ou mecanismos para simplificar as dificuldades do cliente. \\
\hline Relacionamento & Relaciona-se com a experiência do cliente com a empresa. \\
\hline Agregação de valor & Melhorar a forma de captar o valor dos produtos percebido por cliente e fornecedores. \\
\hline Organização & Melhorar a estrutura da empresa \\
\hline Cadeia de formecimento & Incrementar a logística com os formecedores e clientes, sejam internos, sejam externos. \\
\hline Rede & Comunicação entre os elos da cadeia de formecimento. \\
\hline Ambiência Inovadora & $\begin{array}{l}\text { Relaciona-se com os profissionais que compõem a empresa e que colaboram com a cultura da } \\
\text { inovação. }\end{array}$ \\
\hline
\end{tabular}

Tabela 1: Definição das dimensões da inovação. 

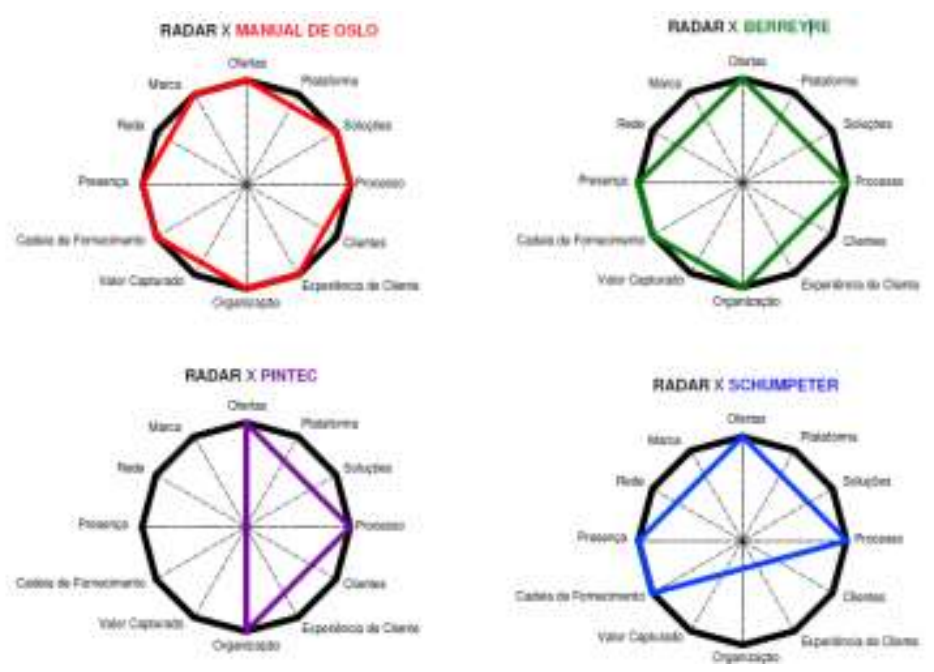

Figura 2: Dimensões da Inovação: diversos modelos

\begin{tabular}{|c|c|}
\hline \multicolumn{2}{|c|}{ DEFINIÇÁO DOS FUNDAMENTOS DA EXCELËNCIA EM GESTÁO } \\
\hline Fundamento & Conceito \\
\hline Pensamento Sistêmico & $\begin{array}{l}\text { Entendimento das relações de interdependência entre os diversos componentes } \\
\text { de uma empresa, bem como entre a empresa e o ambiente externo. }\end{array}$ \\
\hline Aprendizado Organizacional & Busca e alcance de um novo patamar de conhecimento para a empresa. \\
\hline Cultura de Inovação & $\begin{array}{l}\text { Promoção de um ambiente favorável à criatividade, experimentação e imple- } \\
\text { mentação de novas ideias. }\end{array}$ \\
\hline Liderança e Constância de Propósitos & Atuação de forma aberta, democrática, inspiradora e motivadora das pessoas. \\
\hline Orientação por Processos e informações & $\begin{array}{l}\text { Compreensão e segmentação do conjunto de atividades e processos da empre- } \\
\text { sa, sendo que a tomada de decisões e a execução de ações devem levar em } \\
\text { consideração as informações disponiveis. }\end{array}$ \\
\hline Visão do Futuro & Compreensão dos fatores que afetam a empresa, visando à sua perenização. \\
\hline Geração de Valor & Alcance de resultados consistentes, assegurando a perenidade da empresa. \\
\hline Valorização das Pessoas & $\begin{array}{l}\text { Estabelecimento de relações com as pessoas, criando condições para que elas } \\
\text { se realizem pessoal e profissionalmente. }\end{array}$ \\
\hline $\begin{array}{l}\text { Conhecimento sobre o Cliente e o } \\
\text { Mercado }\end{array}$ & $\begin{array}{l}\text { Conhecimento e entendimento do cliente do mercado, visando à criação de } \\
\text { valor, de forma sustentada para o cliente e maior competitividade. }\end{array}$ \\
\hline Desenvolvimento de Parcerias & $\begin{array}{l}\text { Desenvolvimento de atividades em conjunto com outras com outras empresas, } \\
\text { com o objetivo de obter benefícios para ambas as partes. }\end{array}$ \\
\hline Responsabilidade Social & $\begin{array}{l}\text { Atuação que se define pela relação ética e transparente da empresa com todos } \\
\text { os seus públicos de relacionamento, voltada ao desenvolvimento sustentável da } \\
\text { sociedade. }\end{array}$ \\
\hline
\end{tabular}

Tabela 2: Definição dos fundamentos da gestão 
A Figura 2 mostra as dimensões da inovação na visão de vários autores e trabalho em comparação com o modelo de Sawhney [4], [12].

\subsection{Os Critérios da Excelência - gestão empresarial}

Utilizou-se também, além do questionário do radar da inovação já apresentado, a metodologia do sistema de autoavaliação, que foi elaborado com base no modelo de excelência da gestão (MEG) da FNQ. É uma ferramenta para realizar um diagnóstico objetivo do estado atual da gestão da empresa e permite a medição do grau de maturidade da gestão por meio de quatro etapas, sendo: Gestão da Empresa, Características do Comportamento Empreendedor, Práticas de Responsabilidade Social e Práticas de Inovação.

A primeira etapa, Gestão da Empresa, é composta por oito critérios de excelência, a saber: Liderança, Estratégias e Planos, Clientes, Sociedade, Informações e Conhecimento, Pessoas, Processos e Resultados. O MEG tem como base os 11 Fundamentos da excelência em Gestão, que são conceitos reconhecidos mundialmente, encontrados em empresas que já atingiram patamares de excelência ou que caminham nessa direção. Esses fundamentos são aplicáveis a qualquer empresa, uma vez que tratam, de forma genérica, dos mais modernos conceitos de gestão e estão definidos na Tabela 2 .

\section{Metodologia}

A metodologia aplicada neste artigo passa por três etapas, a saber: aplicação dos questionários; tratamento das informações e construção das tabelas e gráficos. A primeira etapa da pesquisa visa captar dados sobre cada dimensão a partir da aplicação do questionário Radar da Inovação e dos critérios de excelência do questionário de Autoavaliação. Sendo o radar da inovação composto de 40 construtos agrupados em 13 categorias, as quais coincidem com as dimensões da inovação propostas por Sawhney [12], [4] e mais a dimensão ambiência inovadora Bachmann [13] e o de autoavaliação por 58 construtos agrupados em quatro categorias. Os questionários foram aplicados em uma amostra aleatória com 40 micros e pequenas empresas do setor industrial de alimentos da região metropolitana e da cidade do Recife. O setor foi escolhido no tocante às possibilidades de inovar. Tais questionários foram utilizados para validar e testar o método de determinação do Grau de Inovação e o Desempenho da Gestão. Os questionários foram respondidos pelos empresários das organizações selecionadas na amostra, com o apoio de um pesquisador vinculado ao Programa Agente Local de Inovação promovido pelo Serviço Brasileiro de Apoio às Micro e Pequenas Empresas (SEBRAE) do Estado de Pernambuco. O modelo aqui proposto surge como uma evolução natural do Grau Global de Inovação obtido como a média aritmética das 13 dimensões da inovação de Bachmann [13], bem como do desempenho da gestão. De acordo com Ketokivi \& AliYrkkö [14] ações de inovação têm um impacto em múltiplas dimensões do radar, mas de forma distinta para cada empresa. Estes autores sinalizaram que independe da origem da inovação, quer seja no lançamento de um novo produto ou uma estratégia de venda, ou outra ação, haverá um incremento das dimensões. Entretanto, a propagação do impacto entre as dimensões tem efeito distinto entre cada empresa.

\subsection{Aplicação}

$\mathrm{Na}$ Tabela 3 são apresentadas as estatísticas das dimensões da inovação, sendo a nota 5 a pontuação máxima a ser obtida, a média dos resultados são parecidas em quase todas as dimensões, assim como o valor mínimo, os valores máximos alcançados que se destacam na tabela são referentes as dimensões plataforma, marca e relacionamento.

\begin{tabular}{|c|c|c|c|c|}
\hline \multirow{2}{*}{$\begin{array}{c}\text { Dimensão do Radar } \\
\text { da } \\
\text { Inovação }\end{array}$} & \multicolumn{4}{|c|}{$\begin{array}{c}\text { Indústria de Alimentos - } \\
40 \text { empresas }\end{array}$} \\
\hline & $\begin{array}{l}\text { Pontuação } \\
\text { Máxima }\end{array}$ & Média & Máximo & Mínimo \\
\hline Oferta & 5,0 & 2,0 & 2,6 & 1,0 \\
\hline Plataforma & 5,0 & 4,7 & 5,0 & 3,0 \\
\hline Marca & 5,0 & 3,0 & 4,0 & 2,0 \\
\hline Clientes & 5,0 & 1,5 & 2,3 & 1,0 \\
\hline Soluções & 5,0 & 1,5 & 3,0 & 1,0 \\
\hline Relacionamento & 5,0 & 1,5 & 4,0 & 1,0 \\
\hline Agregação de valor & 5,0 & 1,1 & 2,0 & 1,0 \\
\hline Processos & 5,0 & 1,5 & 2,7 & 1,0 \\
\hline Organização & 5,0 & 1,2 & 2,3 & 1,0 \\
\hline $\begin{array}{l}\text { Cadeia de formecimen- } \\
\text { to }\end{array}$ & 5,0 & 1,0 & 1,0 & 1,0 \\
\hline Presença & 5,0 & 1,1 & 3,0 & 1,0 \\
\hline Rede & 5,0 & 1,2 & 3,0 & 1,0 \\
\hline
\end{tabular}

Tabela 3: Estatísticas das dimensões da inovação média do setor.

Na Tabela 4 consta o desempenho da gestão das 40 empresas do setor industrial de alimentos, ambos obtidos a partir dos questionários aplicados. 


\begin{tabular}{|l|r|r|r|r|}
\hline \multirow{2}{*}{$\begin{array}{c}\text { Desempenho } \\
\text { da Gestão }\end{array}$} & \multicolumn{4}{|c|}{ I0 empresas } \\
\cline { 2 - 5 } & Máxima & Média & Máximo & Mínimo \\
\hline Liderança & 15,00 & 4,90 & 10,15 & 1,50 \\
\hline Estratégias e Planos & 9,00 & 1,04 & 4,06 & 0,00 \\
\hline Clientes & 9,00 & 2,68 & 6,39 & 1,08 \\
\hline Sociedade & 6,00 & 2,08 & 5,00 & 0,60 \\
\hline $\begin{array}{l}\text { Informações e } \\
\text { Conhecimentos }\end{array}$ & 6,00 & 1,51 & 3,16 & 0,45 \\
\hline Pessoas & 9,00 & 2,76 & 4,77 & 1,62 \\
\hline Processos & 16,00 & 4,76 & 6,60 & 2,40 \\
\hline Resultados & 30,00 & 1,46 & 16,50 & 0,00 \\
\hline
\end{tabular}

Tabela 4: Estatísticas do desempeno da gestão média do setor.

Uma rápida avaliação mostra que nas dimensões: plataforma (conjunto de componentes comuns, métodos de montagem ou tecnologias que são usadas, de forma "modular", na construção de um portfólio de produtos, a habilidade em usar uma mesma plataforma para oferecer um maior número de produtos reflete uma maior capacidade inovadora) e marca (símbolos, palavras (slogan) ou formatos pelos quais uma empresa transmite sua imagem, ou promessa, aos clientes, a inovação nesta dimensão implica, por exemplo, em usufruir da marca para alavancar outras oportunidades de negócio ou, inversamente, usar outros negócios para valorizar a marca), o setor está acima da média. Esta vantagem pode ser atribuída às características do setor que têm a habilidade de utilizar os recursos físicos e de conhecimento para produção ou atendimento para servirem a mais de uma família de produtos, assim como, oferecer o mesmo produto em mais de uma versão para atingir novos mercados ou grupos de clientes.

Quanto à dimensão marca, podemos avaliar que as empresas do setor tem a característica de utilizar a marca em propaganda ou associada a outros tipos de produtos ou negócios. Observa-se ainda a preocupação das organizações em registrar a marca no órgão competente. Já no desempenho da gestão, o setor não apresenta resultados representativos para nenhum critério medido. Analisando rapidamente, o critério Resultados, esses são apresentados pela empresa, sendo decorrência direta de tudo o que a empresa tem ou faz para cumprir os demais critérios da gestão, são relativos aos clientes, colaboradores, aos processos principais do negócio e financeiros. Quando solicitados aos responsáveis, não há registros nas empresas se os resultados dos dois ou três últimos anos demonstram piora em relação aos demais anos, com uma tendência desfavorável, se apresentam melhoras, demonstrando que a situação, quando comparada aos outros anos, é favorável ou mesmo se os resultados dos três últimos anos mostram melhoria constante e sustentada.

No radar de inovação mostrado na Figura 3, as dimensões agregação de valor, organização, cadeia de fornecimento e presença são as que menos passam por inovações nesse setor.

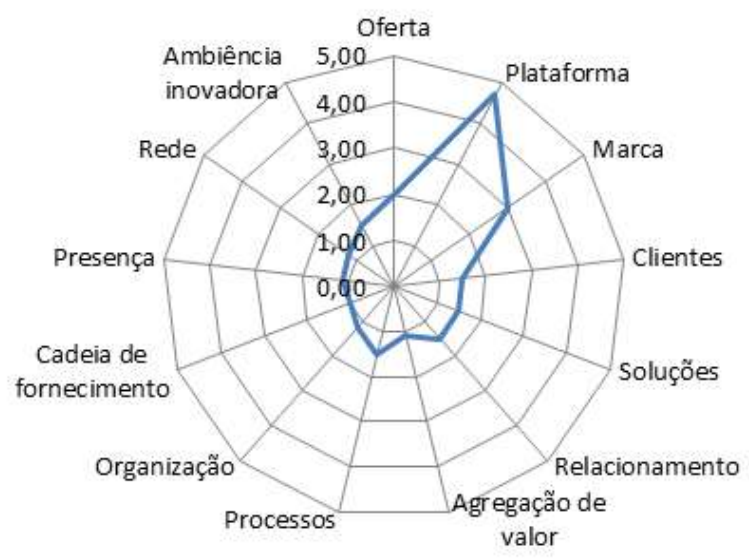

Figura 3: Radar de inovação médio para a indústria de alimentos.

O desempeno da gestão na Figura 4 apresenta os critérios de liderança e processo como os mais bem avaliados e trabalhados nas gestões das empresas amostradas.

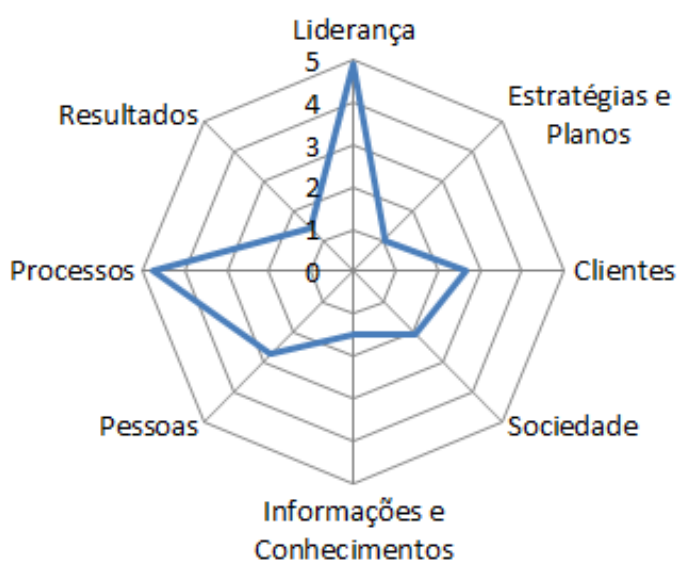

Figura 4: Desempenho da Gestão médio para a indústria de alimentos.

Nota-se uma tendência favorável do setor à inovação quando o desempenho da gestão é mais desenvolvido. O mesmo pode ser observado na Tabela 5 que mostra o grau de inovação e desempenho da gestão global de cada empresa pesquisada. 


\begin{tabular}{|c|c|c|}
\hline Empresas & $\begin{array}{c}\text { Desempenho } \\
\text { da Gestão }\end{array}$ & $\begin{array}{l}\text { Grau de } \\
\text { Inovação }\end{array}$ \\
\hline 38 & 61,10 & 2,20 \\
\hline 4 & 53,69 & 2,10 \\
\hline 31 & 51,10 & 2,00 \\
\hline 25 & 51,10 & 1,90 \\
\hline 36 & 34,99 & 2,50 \\
\hline 20 & 34,30 & 2,30 \\
\hline 34 & 30,38 & 1,90 \\
\hline 16 & 29,96 & 2,00 \\
\hline 19 & 28,46 & 2,00 \\
\hline 39 & 28,24 & 2,30 \\
\hline 33 & 25,08 & 2,00 \\
\hline 21 & 23,83 & 2,10 \\
\hline 23 & 23,76 & 2,20 \\
\hline 35 & 23,14 & 1,60 \\
\hline 11 & 22,72 & 1,70 \\
\hline 3 & 20,92 & 1,90 \\
\hline 17 & 20,47 & 2,00 \\
\hline 26 & 20,47 & 1,70 \\
\hline 18 & 20,15 & 1,50 \\
\hline 29 & 19,70 & 1,40 \\
\hline 6 & 19,25 & 1,80 \\
\hline 32 & 19,25 & 1,80 \\
\hline 14 & 19,20 & 1,80 \\
\hline 10 & 18,52 & 1,80 \\
\hline 5 & 18,52 & 1,70 \\
\hline 8 & 18,52 & 1,70 \\
\hline 12 & 18,52 & 1,70 \\
\hline 22 & 18,52 & 1,70 \\
\hline 40 & 18,44 & 1,60 \\
\hline 37 & 18,08 & 1,70 \\
\hline 30 & 17,69 & 1,70 \\
\hline 2 & 17,38 & 1,40 \\
\hline 28 & 17,37 & 1,60 \\
\hline 9 & 16,96 & 1,50 \\
\hline 27 & 16,25 & 1,60 \\
\hline 15 & 14,43 & 1,50 \\
\hline 1 & 13,02 & 1,40 \\
\hline 24 & 12,93 & 1,50 \\
\hline 13 & 11,90 & 1,40 \\
\hline 7 & 10,74 & 1,40 \\
\hline
\end{tabular}

Tabela 5: Total das empresas amostradas em ordem decrescente do resultado do desempenho da gestão, demonstrando que o valor é diretamente proporcional à capacidade de inovar da organização.
A Figura 5 mostra ainda o potencial do setor em relação à inovação. As empresas de indústria de alimentos possuem um benchmarking ativo, o que ajuda no processo de inovação, no entanto, o setor não demonstra um potencial para melhorar o desempenho da gestão.

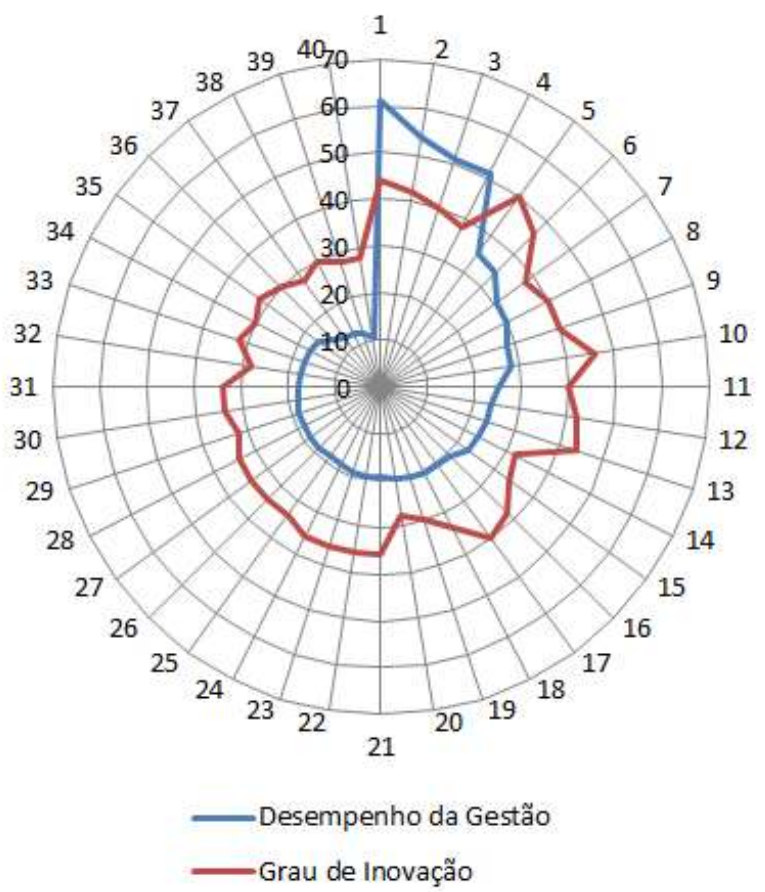

Figura 5: Radar de inovação e desempenho da gestão referencial para o setor de indústria de alimentos.

A Tabela 6 apresenta as estatísticas das dimensões da inovação média do setor e desempenho da gestão, onde no grau de inovação é calculado a média das dimensões da inovação, já o desempenho da gestão por uma pontuação máxima previamente estabelecida em que a soma dos resultados é cem por cento.

\begin{tabular}{|c|c|c|}
\cline { 2 - 3 } \multicolumn{1}{c|}{} & $\begin{array}{c}\text { Pontuação } \\
\text { Máxima }\end{array}$ & $\begin{array}{c}\text { Resultado do } \\
\text { Setor de Indústria } \\
\text { de Alimentos }\end{array}$ \\
\hline $\begin{array}{c}\text { Grau de } \\
\text { inovação }\end{array}$ & 5,00 & 1,70 \\
\hline $\begin{array}{c}\text { Desempenho } \\
\text { da gestão }\end{array}$ & 100,00 & 23,97 \\
\hline
\end{tabular}

Tabela 6: Estatísticas das dimensões da inovação e critérios de gestão por média do setor. 


\section{Conclusões}

Mudanças nas organizações, desenvolvimento de novos produtos e/ou serviços, melhorias em processos entre outras atividades realizadas na empresa não acontecem sozinhos. Diante dessa necessidade, práticas inovadoras devem ser estimuladas e fortalecidas por meio de parcerias, colaboradores e dirigentes, visando a vantagem competitiva. Essa vantagem é traduzida em avanços gerais, ou seja, não apenas para empresas mas, para a sociedade, e por isso deve ser incentivada.

Considerando ser indiscutível a relevância da inovação no desenvolvimento de uma nação, região ou localidade, também o é sua forma de medir. Sobretudo para que as empresas, e instituições de fomentos tenham uma referência para identificar que ações impulsionadoras de inovação surtem efeito. Nesta linha explica-se o sucesso do radar de inovação no sentido de nortear a medida da inovação, não apenas no sentido da inovação associada a novos produtos, mas no sentido mais amplo. Qual seja agregar valor à organização por modelos adaptados às características do setor e que sejam flexíveis ao próprio ambiente onde essas empresas estão localizadas e ao mesmo tempo serem sustentáveis.

Com as mudanças no comportamento dos consumidores é necessária a adequação do setor de indústria de alimentos no intuito de introduzir e diversificar produtos/serviços para acompanhar os clientes. Quanto à gestão do negócio, está mais sofisticado. O estilo empírico de administrar ficou no passado. A gestão está cada vez mais planejada, profissional e tecnológica. É necessário direcionar estratégias de investimentos, especialmente em termos de equipamentos, matérias-primas, layout, atendimento, mix de produtos, entre outros. Nesse sentindo a inovação é parte fundamental no desenvolvimento da empresa para mantê-la no mercado de atuação e melhorar continuamente seus processos.

Todo o processo de desempenho de gestão de uma organização visa preparar a empresa para alcançar os objetivos, ganhar competitividade, obter melhor visibilidade do mercado e base para implantar o processo de gestão da inovação. A busca constante por inovação e desenvolvimento deve integrar a agenda de estratégias de negócios de qualquer empresa independente do porte.

Visto que as micros e pequenas empresas são parte essencial do processo de desenvolvimento do País para a geração de renda e qualidade de vida das pessoas, bem como para o crescimento econômico e o desenvolvimento sustentável de toda sociedade brasileira, microempresas e empresas de pequeno porte respondem por mais de $95 \%$ das indústrias e geram cerca de $50 \%$ dos empregos do setor industrial, $21,8 \%$ dos salários pagos pela indústria e $15 \%$ do PIB do setor segundo dados do Instituto Brasilei- ro de Geografia e Estatística (IBGE). É importante promover a melhoria no ambiente de negócios nas várias áreas de atuação.

Diante de um mercado dinâmico e competitivo, inovar é fundamental, pois agrega valor ao negócio trazendo resultado positivo, permite oferecer o melhor para o cliente e identifica oportunidades de melhoria e desenvolvimento contínuo para organização, incluindo o posicionamento estratégico. Para a implantação e manutenção da inovação, se faz necessário a base da gestão empresarial, visto que a cultura inovadora considera a liderança, estratégias e planos, clientes, sociedade, informações e conhecimentos, pessoas, processos e resultados como norteadores para obter resultados satisfatórios.

As evoluções tecnológicas são a prioridade dos empreendedores do setor quando o assunto é inovação, de acordo com os dados levantados. Mas isso não se restringe a máquinas e equipamentos. Os investimentos em inovação são observados também em novos produtos e marketing, que são igualmente importantes. Certificação, formalização dos estabelecimentos e principalmente qualificação de mão de obra são algumas das necessidades encontradas, sobretudo nas micro e pequenas empresas no que se refere a gestão do negócio.

O resultado quantitativo da inovação obtido de cada empresa por meio do grau da inovação permite identificar que está diretamente ligado ao desempenho da gestão, ou seja, quanto mais desenvolvida for a gestão da empresa mais capacidade para inovar há na organização. De forma geral, as empresas demonstram possibilidades para inovar, mas esbarra em dificuldades cotidianas que seriam facilmente tratadas se houvesse um maior desempenho quanto ao gerenciamento de atividades básicas atreladas a gestão empresarial. Assim, a partir dos resultados, é necessário investir em ações dirigidas para gestão da empresa, para obtenção de resultados satisfatórios por meio dos objetivos estabelecidos. Os processos de desempenho da gestão e gestão da inovação podem ser desenvolvidos paralelamente. Resultados esses que serão percebidos pelos clientes e alta direção da empresa, tornando-se uma organização diferenciada com evolução sustentável e competitividade estabelecida.

\section{Referências}

[1] MIRSHAWKA, V. Criando Valor Para o Cliente, Makron Books Editora Ltda, 1993.

[2] SENGER, P., SCHARMER, C. O., JAWORSKI, J. e FLOWERS, B. S. Presence: an exploration of profound change in people, organization and society. Currency Books 2006. 
[3] SCHUMPETER, J. A. The Theory of Economic Development: An Inquiry into Profits, Capital, Credit, Interest,and the Business Cycle. New York, Oxford University Press.1984.

[4] SAWHNEY, M. e CHEN, J.. Defining and Measuring Business Innovation: The Innovation Radar. Electronic copy available at: http://ssrn.com/abstract=1611264, 2010.

[5] GARCIA, R. e CALANTONE. R. A critical look at technological innovation typology and innovativeness terminology: a literature review. Journal of Product Innovation Management 19(2): 110-132. 2002.

[6] MCDERMOTT, C. M. e O'CONNER, G. C. . Managing radical innovation: an overview of emergent strategy issues. Journal of Product Innovation Management 19: 424-438.2002.

[7] HAUSER, J., TELLIS, G. J. e GRIFFIN, A.. Research on Innovation: A Review and Agenda for Marketing Science. Marketing Science 25(6): 687-717. 2006.

[8] HAN, J. K., KIM N. e SRIVASTAVA. R. K.. Market Orientation and Organizational Performance: Is Innovation a Missing Link? Journal of Marketing 62(4): 30-45. 1998.

[9] TUSHMAN, M. e D. NADLER. Organizing for Innovation. California Management Review 28(3): 74-92. 1986.

[10] GARCIA, J. G. "Um estudo sobre as formas de inovação e os critérios de avaliação dos prêmios de inovação." Dissertação de mestrado. Universidade de Caxias do Sul., 2008.

[11] OSLO - Organização para Cooperação Econômica e Desenvolvimento. Manual de Oslo: Proposta de Diretrizes para Coleta e Interpretação de Dados sobre Inovação Tecnológica. Versão FINEP, 2004.

[12] SAWHNEY, M., WOLCOTT, R. C. e ARRONIZ, I.. The 12 Different Ways for Companies to Innovate. MIT Sloan Management Review 47(3): 75-81. 2006.

[13] BACHMANN, D. L. e DESTEFANI, J. H.. Metodologia para estimar o grau das inovações nas MPE. Curitiba, 2008.

[14] KETOKIVI, M. e ALI-YRKKÖ, J., Innovation does not equal R\&D: strategic innovation profiles and firm growth. Helsinki, ETLA, E. T., The Research Institute of the Finnish Economy, 22 p. (Keskusteluaiheita, Discussion Papers; ISSN 0781-6847; no. 1220)., 2010. 